\title{
4 Family co-occurrence and firm productivity
}

\author{
Evans Korang Adjei and Rikard Eriksson
}

\section{Introduction}

Does family co-occurrence in businesses affect firm productivity? While this general question is at the core of research in family business, previous investigations are plagued by inconclusive answers. Several scholarly works have found variegated impacts of family co-occurrence on firm productivity (e.g., Gedajlovic, Carney, Chrisman, \& Kellermanns, 2012). While some studies have argued that family co-occurrence in businesses, especially in family firms, helps promote localized learning and alleviate conflicts of interest between owners and managers (Chrisman, Chua, \& Litz, 2004; Jensen \& Meckling, 1976), others have found family involvement to be detrimental for firm productivity due to moral hazards and adverse selection (Schulze, Lubatkin, Dino, \& Buchholtz, 2001).

Despite the ambiguity regarding the role of family involvement in business, kinship ties still constitute an important part of the recruitment process. Although a systematic cross-country mapping of family involvement in business is missing, family co-occurrence constitutes about $14 \%$ of all employment in Sweden (Holm, Westin, \& Haugen, 2017). This finding supports the notion that meritocracy in the labour market co-exists with other types of hiring practices (Adjei, 2018), such as nepotism. Despite the obvious representation of family ties in the workplace and research indicating that family typologies play a major role in regional development in terms of gross domestic product (GDP) per capita (Duranton, Rodríguez-Pose, \& Sandall, 2009), the relationship between family co-occurrence and firm productivity is relatively under-researched. Basco (2015), for instance, argues that regional development studies have neglected to investigate the family's role in firm behaviour and the subsequent consequences for regional economic and social development. While some regional development studies have recognized the role of social capital in shaping competitive advantages (Saxenian, 1994), the potential role of familial relationships has often been studied only through case studies (Gurrieri, 2008; Johannisson et al., 2007).

Consequently, because there is hardly an aspect of society that is not affected by the family (Alesina \& Giuliano, 2014), we focus on the link 
between family co-occurrence and firm productivity. Specifically, in this chapter, we investigate the combined effect of the type of family tie, the skills involved, and the regional context on firm productivity. To address this aim, we analyze a Swedish dataset containing different relational longitudinal population registers from 1995 to 2012. We found a significant and positive relationship between family co-occurrence and firm productivity. However, this relationship varies across geographical space and types of familial relationships.

\section{Literature review: family co-occurrence and firm productivity}

The presence of family co-occurrence in firms (i.e., the presence of familial relationships inside a firm, including among co-workers and between employees and owners) is a function of the effects of agglomeration economies and hiring practices. Manifold studies have argued that because competition is high in larger regions, only the most productive firms and workers select each other (Bjerke \& Mellander, 2017; Combes et al., 2012; Florida, Mellander, Stolarick, \& Ross, 2012). Therefore, because the most productive firms and skilled workers tend to be located in larger regions, smaller regions might have relatively fewer productive firms and workers (Combes et al., 2012; Glaeser \& Maré, 2001). Due to the spatial sorting of skills into larger regions, firms in smaller regions with thinner labour markets are likely to have alternative hiring strategies. For instance, these firms may resort to hiring through referrals and family networks (Montgomery, 1991), resulting in more and stronger family ties at the firm level. Hence, we expect that the phenomenon of family co-occurrence is more prevalent in smaller and more peripheral regions compared to larger urban regions.

Moreover, the effects of globalization have increased migration patterns, leading to high movement into larger regions because of the availability of job opportunities. This trend has torn families apart and weakened familial relationships. However, because smaller regions facilitate frequent face-toface interactions, social network density among economic actors tends to be relatively higher in smaller regions compared to in larger ones (Lengyel \& Eriksson, 2016). Therefore, it is reasonable to expect that in smaller regions, stronger and more trustful familial relationships are likely to be found in firms. Supporting this argument, Holm et al. (2017) found low levels of kinship density in workplaces in Sweden's metropolitan regions, somewhat high levels in intermediate regions (urban regions), and higher levels in remote and sparsely populated areas (rural or small regions). They further showed that kinship density decreases with rising education levels, which means that workers with low education are over-represented in workplaces with high kinship density, a phenomenon that is likely highly associated with smaller and/or rural regions.

Considering the prevalence and importance of family co-occurrence across regions, it is important to further analyze the influence of 
family co-occurrence on firm productivity. This potential relationship can be studied through the lenses of learning and agency costs. First, family co-occurrence can enhance localized learning through shared identity and transgenerational knowledge transfer (Wenger, 2000), as well as via joint social arrangements and mutual trust (Boschma, 2005). Since organizational learning involves firm members' ability to create, retain, and share both general and complex knowledge (March, 1991), some level of trust is needed to enhance this process. Promoting kinship or familial relationships among top managers (De Massis, Kotlar, Campopiano, \& Cassia, 2015) increases trust-boosting information symmetry between family managers and encourages learning from others' experience. On the other hand, family co-occurrence can impede or weaken firms' learning capacity, which can in turn negatively affect their productivity. Specifically, a strong family culture can counteract learning by locking family members into a particular way of doing things, hence making them inflexible, resistant to change, and inclined to stick to path-dependent traditions (Chirico \& Nordqvist, 2010) at the expense of their own innovative and learning capacities (Boschma, 2005). Family co-occurrence can also result in the accumulation of similar and suboptimal knowledge, which can also affect firms' learning capacity and, thus, slow down growth at the firm level (Boschma, Eriksson, \& Lindgren, 2009). In other words, the advantages of family co-occurrence are likely to be offset by the low availability of diverse perspectives and knowledge in decision-making processes when family involvement is excessive (De Massis et al., 2015).

Second, family co-occurrence can also influence firm productivity by reducing agency costs. An agency cost is incurred when a principal (owner) has to establish appropriate structural mechanisms to monitor agents (managers) or incentives to promote interest alignment. Moreover, since firms are viewed as sets of contracts among different factors of production, we can expect agency costs to differ between a principal and different agents (Jensen \& Meckling, 1976). Therefore, firm performance in the form of cost minimization and greater efficiency is the outcome of principal-agent relationships involving family agency contracts (Corbetta \& Salvato, 2004). For example, when analyzing Italian small and medium size enterprises (SMEs), De Massis et al. (2015) found that family ownership, family involvement, and the share of family members on top management team have an inverted U-shaped effect on firm productivity. The implication is that while family co-occurrence is likely to influence firm productivity, the effect is non-linear. Additionally, because family agency contracts are based on bonds and sentiments, some argue that they are prone to depart from economic rationality and thus hamper firm performance (Gómez-Mejía, Núñez-Nickell, \& Gutierrez, 2001; Schulze et al., 2001).

Apart from the abovementioned general explanations related to the roles of learning and agency costs in the relationship between family cooccurrence and firm productivity, there are two other important aspects to 
further consider: the types of familial relationships and geographical context. First, the family co-occurrence and firm productivity may also vary depending on the types of familial relationships in firms since different ones represent different types of resources and capabilities in the form of social and human capital (Brannon, Wiklund, \& Haynie, 2013). The family as a social group has complex familial relationships with varying levels of trust and solidarity between family members (Hasenzagl, Hatak, \& Frank, 2018), which can affect their economic behaviours (Wiklund, Nordqvist, Hellerstedt, \& Bird, 2013). The question is whether different types of family cooccurrence affect firm productivity.

Second, while the argument on hiring practices and agglomeration economies seems to suggest a skewed spatial sorting of family co-occurrence in smaller and rural regions (Bjerke \& Mellander, 2017; Combes et al., 2012; Florida et al., 2012), there is limited empirical evidence on the relationship between family co-occurrence and firm productivity across different spatial levels. In other words, the effects of family co-occurrence on firm productivity contains a geographical problem - that is, family co-occurrence may lead to varying outcomes depending on the spatial context. The question is whether family co-occurrence is more likely to positively influence firm productivity in smaller regions than in larger regions since the former are characterized by labour market-matching deficiencies and a lack of variety, coupled with the over-representation of family co-occurrence in firms.

\section{Study design}

\section{Description of data}

To address whether family co-occurrence influences firm productivity, we explored a matched employer-employee dataset containing different relational longitudinal population registers from Statistics Sweden (SCB). The database offers several advantages. First, it is comprehensive, as it records every family in Sweden. Families are identified with a unique family identification code, which further indicates an individual's position in his or her family. Second, it is longitudinal with annual observations of people and firms, thus allowing us to follow both people and firms over time. Third, it contains a wide range of socioeconomic attributes, such as education. Fourth, the geo-referenced attributes of firms/plants and people make it possible to conduct relational investigations at several spatial levels. The basic unit of analysis in the study is the firm. In the database, the term 'plant' represents a separate economic unit (workplace) of a firm. Thus, we use the terms 'plant' and 'firm' interchangeably because our analysis draws on only single-plant firms. With single-plant firms, it is relatively easy to trace the owner. The data included in our analysis are from 1995 to 2012. The industrial classification of the firms was defined by the Swedish Standard Industrial Classification 2002 (SNI02). The geographical reference point for the 

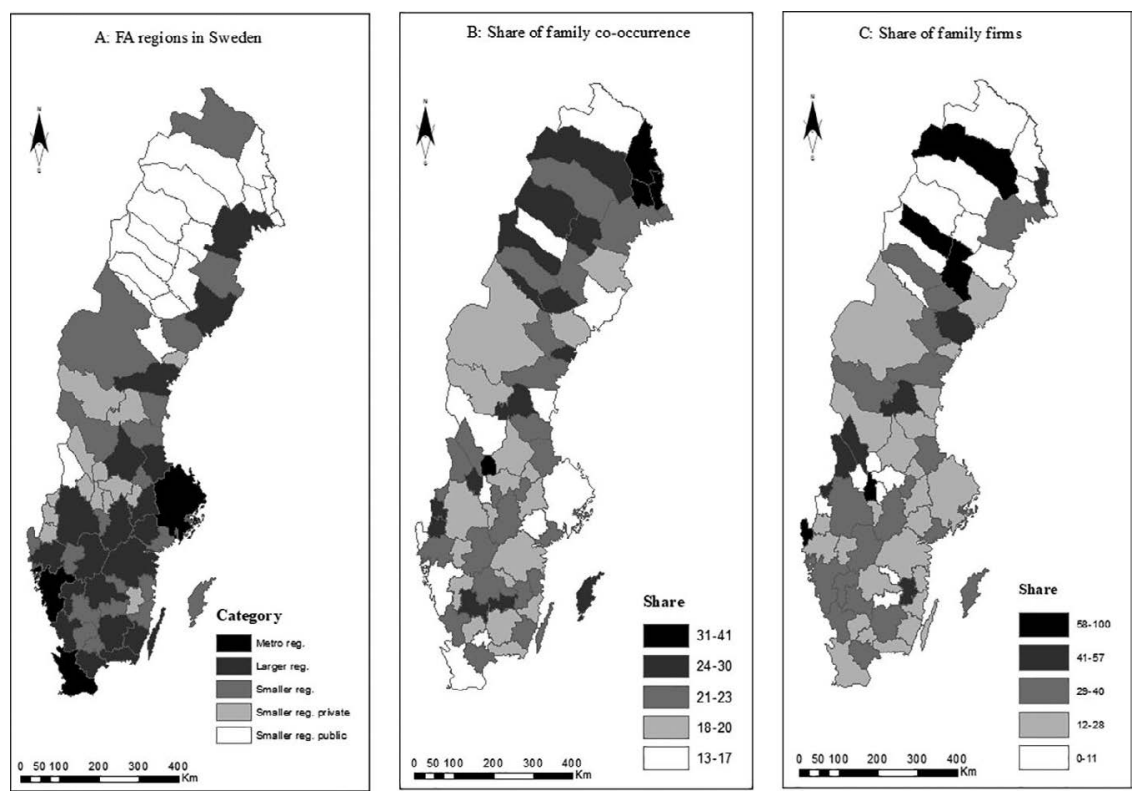

Map 4.1 FA regions (A), the share of family co-occurrence (B), and the share of family firms by region $(\mathrm{C})$.

Source: Adjei, Eriksson, \& Lindgren, 2016; Adjei, Eriksson, Lindgren \& Holm, 2019.

analysis is the local labour market region. Sweden is divided into $290 \mathrm{mu}-$ nicipalities, which are aggregated into 72 local labour market regions called FA regions (see Map 4.1A). The FA regions are based on labour-commuting patterns between municipalities, representing regions where people can live and work without long commuting distances.

\section{Variables}

The dependent variable used in this study is firm labour productivity, measured at the firm level and defined as per capita value-added. 'Value-added' is a straightforward measure of economic or industrial output since it reflects the magnitude of a firm's contribution to the entire economy (Rigby \& Essletzbichler, 2002). Other indicators like patents, citations, and innovation indices cannot necessarily provide this information. Specifically, per capita value-added is an indicator of how a firm utilizes the strengths and skills of its employees; hence, it is an important indicator of business efficiency. We calculated firm productivity by first compensating for the effects of inflation and then dividing deflated firm value-added by the total number of employees in the firm. Logs of the values were used to reduce the effect of skewness in the data. 
Due to the multigenerational nature of the family register, the database provides information on spousal couples (i.e., partners) as well as biological family members, including parents, children, siblings, etc. (the data do not distinguish between biological and adopted children). More importantly, the family register contains unique identification codes indicating the different kinds of relationships in each family. The family and workplace identification codes enabled us to identify family co-occurrence in the same workplace or firm. We adopted a simple definition of family based on the SCB records: consanguineous familial relationships (i.e., blood related) and conjugal familial relationships (i.e., marriage) (Brannon et al., 2013).

We defined two groups of family co-occurrence in a workplace. First, we defined family co-occurrence without a relationship with the firm owner. This was done by randomly selecting an employee from the employee dataset connected to a firm and subsequently checking whether any of his or her family members were present in the same firm. If none of his or her family members were present in the firm, another random employee was selected, until we encounter a family member in the same firm. We then summed the total number of family members in every firm. This randomized approach of selecting family members eliminated systemic bias by giving all families present in a firm an equal chance of being selected. However, since families are heterogeneous and since we identified and selected just one family group for every firm, there is a high probability of randomly selecting a family with specific characteristics (e.g., dysfunctional communication), which could have affected the results.

Second, we defined family co-occurrence with a relationship with the firm owner or entrepreneur. We did so by using the firm owner as the hub connecting family members in the firm. With the family identification and employment identification codes, we linked all family members related to the entrepreneur/owner in the firm. The family members were further grouped based on the type of relationship they had with the entrepreneur (e.g., being his or her spouse, child, or sibling). This approach provided an opportunity to assess the impacts of the family and different familial relationships on firm productivity in family firms.

We controlled for a number of firm-level factors (i.e., firm size, capital intensity, share of higher education) and regional-level factors (i.e., regional size and specialization) known to co-determine productivity (Eriksson \& Lindgren, 2009). Since we are also interested in how familial relationships interact with the skills present in firms, we also controlled for the effects of skill variety. We did so using entropy measurement to define skill variety based on employees' educational background, as first proposed by Boschma et al. (2009). We calculated the similarity in formal skills (SIM) for each plant as the inverted entropy at the three-digit education level.

In Equation (1), $P_{i}^{3}$ is the share of three-digit education categories $i$ and $N^{3}$ is the number of three-digit education categories. A high score means that the firm's in-house formal skills or competencies are more similar, which 
does not promote novelty and productivity. The scores were log-transformed to reduce the effect of the variable's distributional skewness.

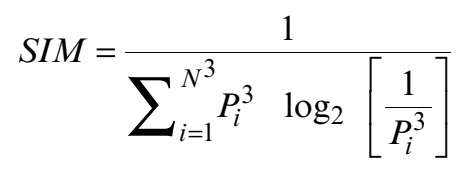

We calculated relatedness in formal skills (REL) as the weighted sum of entropy at the three-digit level within each two-digit education category. $P_{j}^{2}$ in Equation (3) is the share of two-digit education categories, found by summing the shares of all three-digit education categories belonging to $S_{i}^{2} . \mathrm{H}_{\mathrm{j}}$ in Equation (4) is a weight that controls the degree of similarity within the two-/three-digit education categories. A high score indicates higher inhouse formal skill relatedness, which promotes localized learning processes and productivity.

$$
R E L=\sum_{j=1}^{N^{2}} P_{j}^{2} H_{j},
$$

where

$$
P_{j}^{2}=\sum_{i \in S_{i}^{2}} P_{i}^{3},
$$

and

$$
H_{j}=\sum_{i=S_{i}^{2}} \frac{P_{i}^{3}}{P_{j}^{2}} \log _{2}\left[\frac{1}{P_{i}^{3} / P_{j}^{2}}\right] .
$$

The last entropy variable is unrelatedness in formal skills (UNREL), which we measured at the one-digit education level. $P_{i}^{1}$ in Equation (5) is the share of one-digit education categories. A high score indicates higher differences in formal skills (hence, higher unrelatedness), which hinders localized learning and productivity. Due to the de-compositional structure of the variables, research has shown that they do not capture identical features of skill composition (Frenken, Van Oort, \& Verburg, 2007).

$$
U N R E L=\sum_{l=1}^{N^{1}} P_{i}^{1} \log _{2}\left[\frac{1}{P_{i}^{1}}\right] .
$$


With these sets of skill variety, we empirically tested how familial cooccurrence moderates the effects of similar and unrelated sets of skills based on the argument that social ties can reduce cognitive distance between economic actors over time (Boschma, 2005).

Additionally, we controlled for the effects of agglomeration economies with two measures. Given the general claim that firms in co-located industries enjoy externalities not available to more isolated firms (Jacobs, 1969; Marshall, 1920), we controlled for the effects of specialization and urbanization, respectively. We resorted to using a location quotient (LQ), which has been used in the regional science literature to capture the effects of specialization. In Equation (6), $S_{i r}$ is the degree of specialization in industry $i$ in region $r ; E m p_{i r}$ is the number of employees in two-digit industry $i$ in region $r ; E m p_{r}$ is the total number of employees in region $r ; E m p_{i}$ is the number of employees in two-digit industry $I$; and $E m p$ is the total number of employees in Sweden. LQ is a relative measure of the regional share of workers relative to the national average in a specific industry. If $L Q>1$, it implies that the region is more specialized in that industry than the average region. For the effects of general urbanization, we used the log of total regional employment (a representation of employment stock and human capital). We believe that size is a more appropriate measure to capture the effects of urbanization economies than density because of the generally sparsely populated structure of the Swedish economy (Andersson \& Klaesson, 2009). Since the regions considered in this analysis are defined on the basis of commuting distances between dwelling places and municipalities, and not administrative borders like municipalities, we argue that size captures regional potential for interactions. We expect firms located in larger and specialized regions to benefit more from knowledge spillovers and therefore also be more productive than those in small or very diverse regions.

$$
S_{i r}=\frac{E m p_{i r} / E m p_{r}}{E m p_{i} / E m p} .
$$

\section{Empirical model}

Considering the panel nature of the data, two models come to mind: a fixed-effects (FE) model and a random-effects (RE) model - see Equation (7) for the general panel data model. Thus, $\mu_{i t}$ is the product of the individual specific time-invariant effects $\left(u_{i}\right)$ and the time-varying random component $\left(v_{i t}\right)$ - see Equation (8). The FE and RE models both apply the panel structure differently. That is, the FE model applies the within transformation and controls for unobserved heterogeneity by allowing correlation between the individual specific error term and the independent variables. The 
RE model, on the other hand, assumes that variation across observations is random and that there is no correlation between the unique errors and the independent variables. In this case, the Hausman test rejected the hypothesis that there is no correlation between the unique individual specific error term and the independent variables, suggesting that the FE model is more likely to provide consistent estimates than the RE one. Although the Breusch-Pagan Lagrange Multiplier test suggested that the panel effect is minimal, as shown in the considerably lower within variation values for most of the variables, the FE model provides more consistent estimates and was therefore chosen. In Equation (7), $\ln \gamma_{i t}$ is the log average labour productivity (or per capita productivity) in firm $i$ at time $t$.

$$
\begin{aligned}
& \ln \gamma_{i t}=a+\beta^{i} X_{i t}+\mu_{i t} . \\
& \mu_{i t}=u_{i}+v_{i t} .
\end{aligned}
$$

The models include time, region, and industry fixed effects to control for unobserved factors not captured in the models (e.g., year-specific effects, technological differences across industries or sectors, and institutional differences across regions) and cluster-robust standard errors to remedy heteroscedasticity.

\section{Results}

\section{The geography of family co-occurrence}

Map 4.1 shows the different types of FA regions in Sweden (A); the geography of family co-occurrence in the Swedish economy (B); and the share of family firms, defined as firms in which family co-occurrence is directly linked to the owner (C). On average, family co-occurrence constitutes about $18 \%$ of workplace employment and family firms make up $26 \%$ of the sampled firms. From Map 4.1B, we observe that the three metropolitan regions (Stockholm in the east, Gothenburg in the west, and Malmö in the south) are all characterized by a relatively low representation of family co-occurrence. As seen in Table 4.1, the dominant dyadic familial relationship (involving the firm owner and other family members) is the parent-child relationship followed by the spousal/partner and the sibling relationships. The dominant gender in the dyadic familial relationships is male, which is particularly evident in all the relationships. Whereas there are no major differences in age distribution across the different familial relationships, some differences in income and education are observed.

Map 4.2 shows the spatial distribution of the different type of familial relationships (familial relationships with firm owners) in family firms across Sweden. The dominance of parent-child and spousal familial relationships 


\section{Evans Korang Adjei and Rikard Eriksson}

Table 4.1 Description of the dyadic relationships (family relationships/ co-occurrence)

\begin{tabular}{|c|c|c|c|c|c|c|}
\hline $\begin{array}{l}\text { Categorylfamilial } \\
\text { relationships }\end{array}$ & & $\%$ & Entrepreneur & Sibling & Partner & Child \\
\hline $\begin{array}{c}\text { Share of familial } \\
\text { co-occurrence }\end{array}$ & & & - & 12 & 33 & 55 \\
\hline \multirow[t]{2}{*}{ Gender } & Male (\%) & & 88 & 72 & 9 & 73 \\
\hline & Female (\%) & & 12 & 28 & 91 & 27 \\
\hline \multirow[t]{3}{*}{ Average age } & All & & 59 & 51 & 55 & 33 \\
\hline & Male & & 59 & 51 & 58 & 33 \\
\hline & Female & & 60 & 51 & 54 & 33 \\
\hline \multirow{3}{*}{$\begin{array}{l}\text { Mean income } \\
(100 \mathrm{~s}, \mathrm{SEK})\end{array}$} & All & & 3,104 & 2,306 & 2,350 & 2,077 \\
\hline & Male & & 3,163 & 2,417 & 2,546 & 2,216 \\
\hline & Female & & 2,682 & 2,014 & 2,330 & 1,703 \\
\hline \multirow[t]{9}{*}{ Educational level } & All & Low & 33 & 30 & 18 & 18 \\
\hline & & Medium & 58 & 66 & 71 & 76 \\
\hline & & High & 9 & 4 & 11 & 6 \\
\hline & Male & Low & 34 & 33 & 24 & 19 \\
\hline & & Medium & 58 & 64 & 62 & 77 \\
\hline & & High & 8 & 3 & 14 & 4 \\
\hline & Female & Low & 27 & 21 & 18 & 16 \\
\hline & & Medium & 60 & 73 & 71 & 74 \\
\hline & & High & 13 & 6 & 11 & 10 \\
\hline
\end{tabular}

Source: Adjei et. al., 2019.
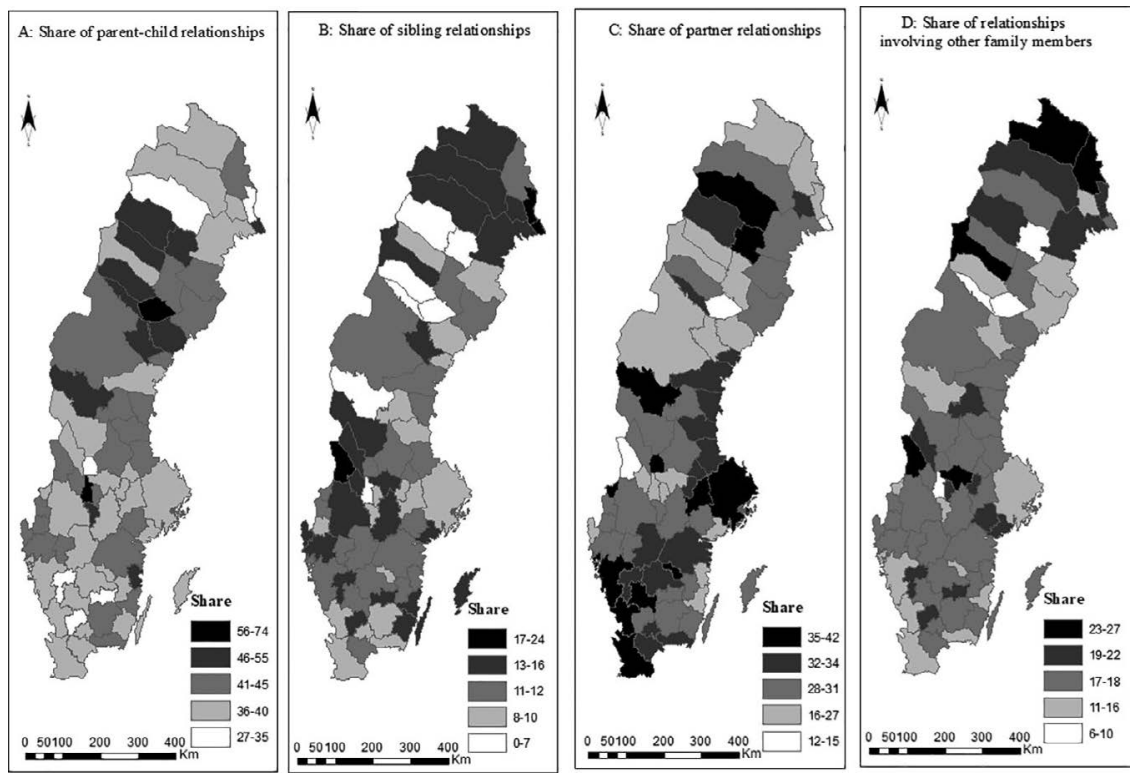

Map 4.2 Regional composition of different familial relationships/co-occurrence. Source: Adjei et al., 2019. 
in the workplace corroborate the argument that small family businesses are indeed nuclear-family based. In summary, although scholars have argued that the family has lost its economic significance (Hollinger \& Haller, 1990; Inglehart \& Welzel, 2010), our findings show that informal family networks still play an important role in firm recruitment even in advanced capitalist societies. This is especially the case in regions with smaller labour market since family hiring may be a cheaper and quicker means of recruitment characterized by higher levels of trust.

\section{Family co-occurrence and firm productivity}

In this section, we present the estimations of the relationship between family co-occurrence and firm productivity. Although we controlled for a number of firm and regional factors, we focus on the relationship between family co-occurrence and firm productivity and how the former moderates the effect of regions and different skillsets on the latter. To simplify the presentation of our findings, we show them in a bar graph for better virtualization of the estimates. ${ }^{1}$ Due to differences in scale across the variables, we present standardized coefficients. This, for example, implies that for every increase of 1 standard deviation in family co-occurrence, productivity increases by 0.0117 standard deviation, assuming the other variables are held constant (see Figure 4.1a).

All the variables in Figure 4.1a are significant and show the expected effects on productivity. The model shows that there is a small albeit positive association between family co-occurrence and firm productivity. This finding corroborates regional familiness arguments that social ties and specific familial relationships can indeed enhance information diffusion and, consequently, firm performance (Basco, 2015). Figure 4.1b further indicates that familial relationships involving children and/or spouses are more likely to positively and significantly affect firm productivity than any others. While research has argued that the family is an important strategic resource, this finding suggests that it is a constellation of different forms of relationships and resources with varying effects on economic firm outcomes. The general positive relationship between family co-occurrence and firm productivity is actually mainly a product of familial relationships involving children and/ or spouses and less so of sibling relationships.

Figure 4.2 focuses on the moderating effects of family co-occurrence. While the effects of family employment on productivity have received significant attention, especially in family business studies, spatial differences of the effects have not received that much attention, even in regional science (Adjei, 2018). The model indicates that family co-occurrence is more likely to positively influence firm productivity in specialized regions than in more diverse ones (Figure 4.2A). Moreover, only familial relationships involving spouses or partners are more likely to affect firm productivity in specialized regions (Figure 4.2B). 


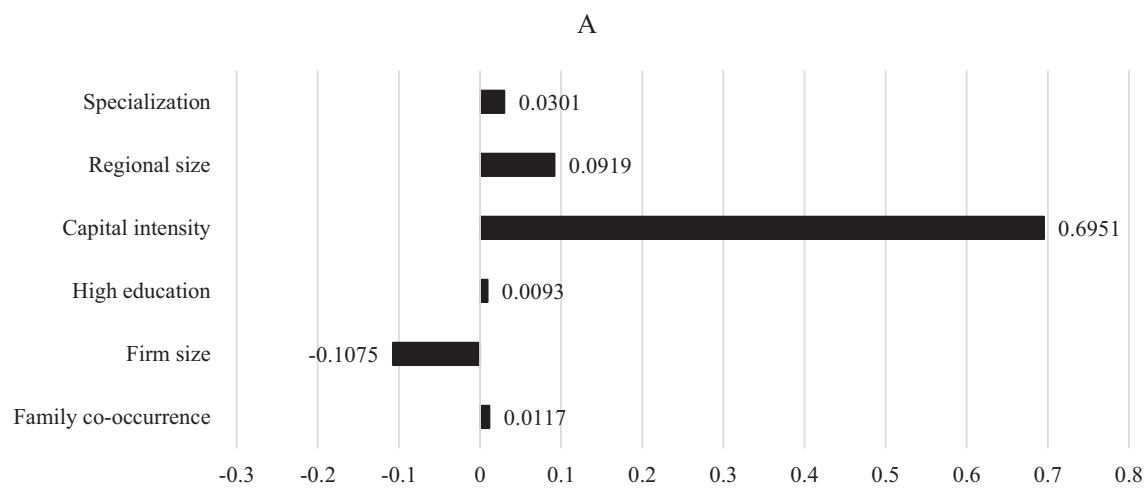

B

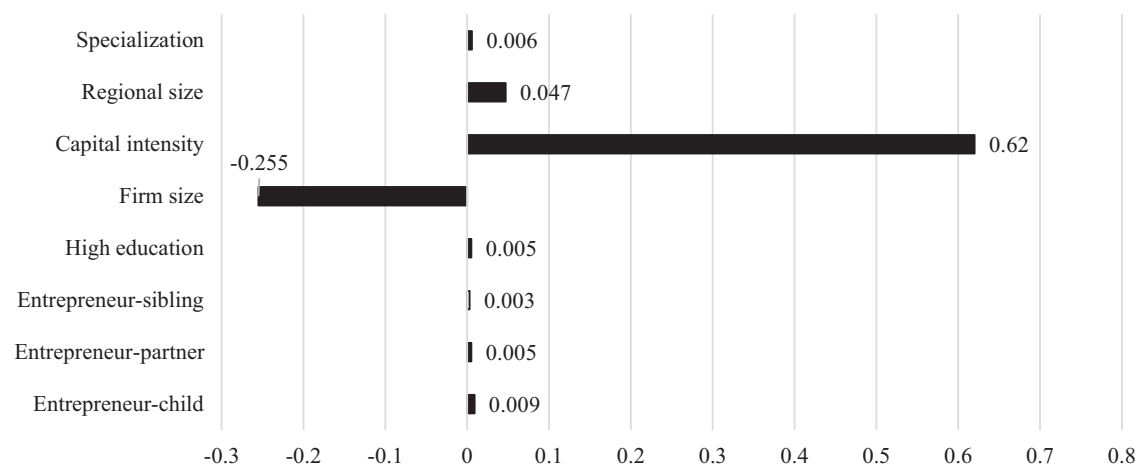

Figure 4.1 Fixed-effects estimates indicating the relationship between family co-occurrence (a: without a relationship with the firm owner; b: with a relationship with the firm owner) and average labour productivity. (a) as expected, capital intensity is positive and significant, as is human capital. However, the effect of firm size on performance is negative and significant, which runs counter to previous findings. The effect is only valid for smaller firms. Moreover, the regional variables indicate that specialization and regional size enhance firm performance. The controls in (B) are same in effects as the controllers in (A); they only differ a little in effect size.

Source: Adjei et al., 2016, 2019.

Figure 4.3 shows how the different familial relationships moderate the effects of skill variety on labour productivity. All the interactions except those involving spousal/partner relationships and parent-child relationships are significant. These results indicate that parent-child familial relationships abate the negative effects of similarity in formal education on productivity. To some extent, the findings show that family firms in which the children 
Family co-occurrenec X High education

Family co-occurrence X Firm size Family co-occurrence X Specialization Family co-occurrence X Regional size Specialization Regional size Capital intensity High education Firm size Family co-occurrence
A

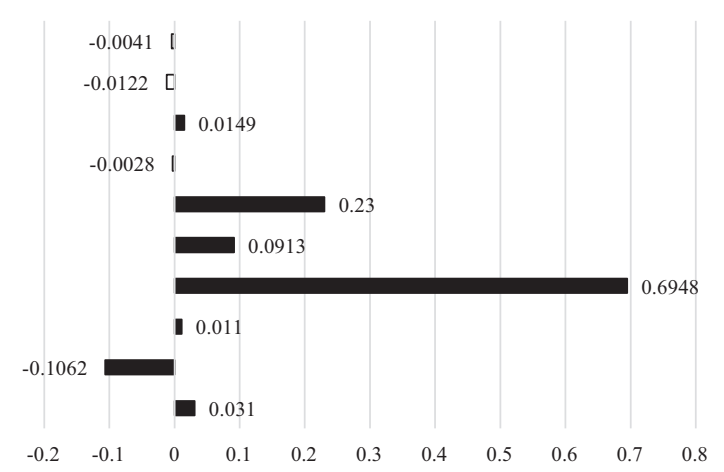

B

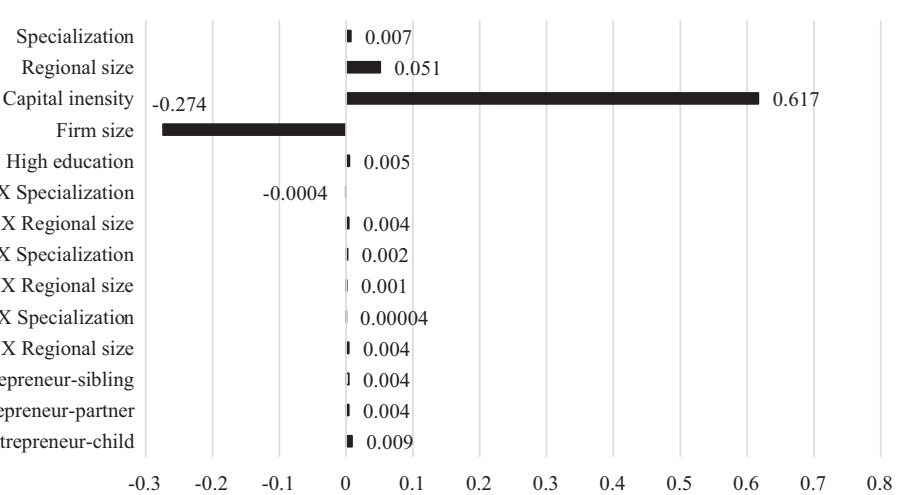

Figure 4.2 Fixed-effects estimates showing the moderating effects of family cooccurrence (a: without a relationship to the firm owner; b: with a relationship with the firm owner) on the relationship between regional size and specialization and average labour productivity.

As expected, the control variables remain stable with the introduction of the interaction terms. Thus, capital intensity is positive and significant, as is human capital. However, the effect of firm size on performance is negative and significant, which runs counter to previous findings. The effect is only valid for smaller firms. Moreover, the regional variables indicate that specialization and regional size enhance firm performance.

Source: Adjei et al., 2016, 2019.

have similar educational levels as their parents are more likely to perform better. The findings also show that familial relationships involving spouses/ partners are positively correlated with related competencies, and also mitigate the negative impacts of similar and unrelated competencies on labour productivity. 


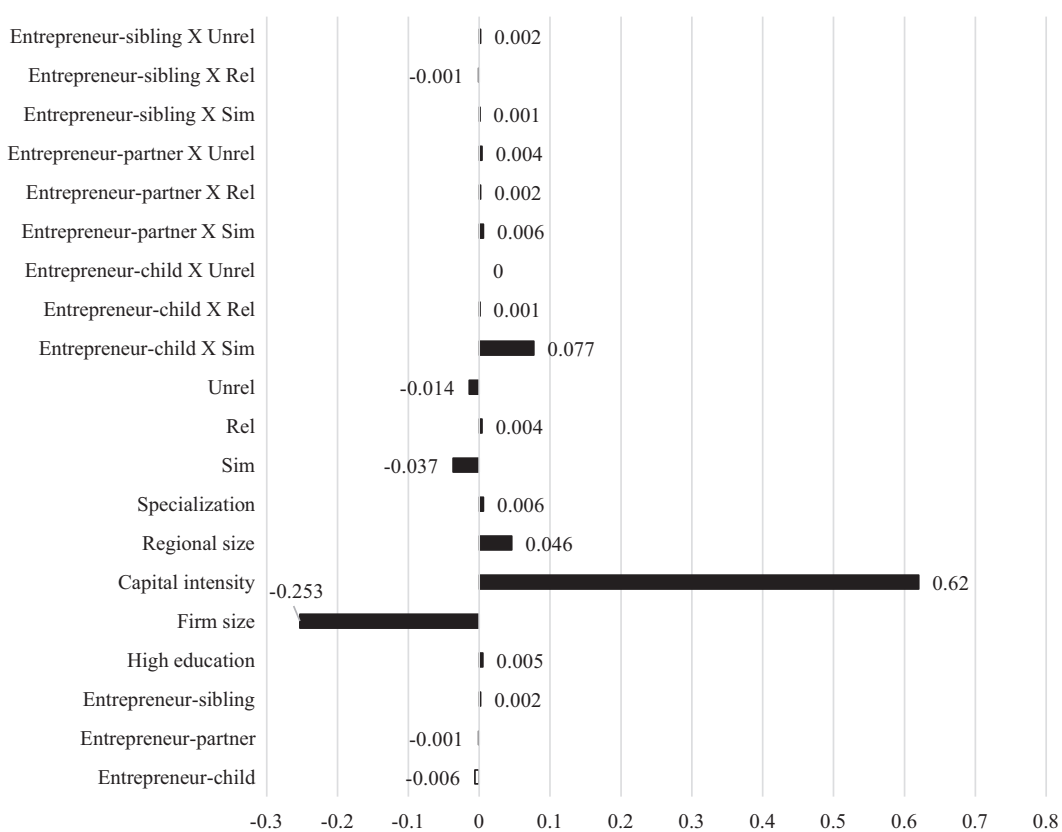

Figure 4.3 Fixed-effects estimates showing the moderating effects of family cooccurrence on relationship between skill variety (formal skills) and average labour productivity.

As expected, capital intensity remains positive and significant, as does human capital. The effect of firm size on performance is, however, negative and significant, which runs counter to previous findings. The effect is only valid for smaller firms. Concerning in-house formal skill variety, our results are in line with previous studies, showing that similarity in formal skills (SIM) (significant and negative) and unrelatedness in formal skills (UNREL) (significant and negative) have a negative impact on productivity, while relatedness in formal skills (REL) enhances performance due to potential complementarities that facilitate interactive learning. The regional variables indicate that specialization and regional size enhance firm performance. Source: Adjei et al., 2019.

\section{Concluding remarks}

The aim of this chapter was to analyze the effects of family co-occurrence on firm productivity. We looked at two groups of family co-occurrences: (1) general family co-occurrence (i.e., the presence of family members within workplaces) and (2) family firm co-occurrence (presence of family members with relationships with firm owners). This selection of two groups is motivated by the assumption that these varied types of family co-occurrence may provide different environments for learning and alternative incentives to reduce agency costs with corresponding effects on firm productivity. 
Based on data on a sample of Swedish SMEs, our results suggest that family co-occurrence is over-represented in workplaces in smaller regions. In other words, we found family co-occurrence to be less common in larger and more diverse regions. This finding is likely driven by the spatial sorting of skilled individuals and firms (Bjerke \& Mellander, 2017; Combes et al., 2012; Florida et al., 2012), such that familial relationships are more prevalent in smaller and relatively thinner labour markets due to labour market imperfections. This finding shows that family contacts and networks may be an important mechanism for finding jobs in the Swedish labour market (Korpi, 2001) for two reasons. First, family contacts can compensate for the relative shortage of regional agglomeration economies and variety of skills (Puga, 2010). Second, family contacts and networks can facilitate the transgenerational intention of human capital transmission (Riggio \& Saggi, 2015).

Dominant dyadic familial relationships are characterized by the presence of the owner with other family members, such as with children or a partner/ spouse. Other familial relationships, such as relationships with siblings or other family members, are less common. The dominance of parent-child and spousal familial relationships in the workplace corroborates the argument that small family firms are indeed nuclear-family based. For family members co-occurring in the same workplace, we found that female family members have relatively higher education levels than their male counterparts. Common among the discussions on job following and family co-occurrence (i.e., children in the same workplace as their parents) has been job followers' low educational levels. However, our finding shows that relatively few children in the same workplace as their parents have low education levels. This finding dispels the argument that children who follow in their parents' career footsteps have lower education levels (Kramarz \& Nordström-Skans, 2014), but rather suggest that this job following may be a mechanism for the transmission of specific forms of human capital (Riggio \& Saggi, 2015).

Regarding our main research question, we find that family co-occurrence is indeed related to firm productivity. Namely, the mere co-occurrence of family members has a general positive effect on firm productivity. However, the main contribution of this book chapter is the fact that we can show the varying benefits of family co-occurrence across space and types of familial relationships.

First, family co-occurrence is more likely to positively influence firm productivity in specialized regions compared to more diverse regions. This finding builds on Gordon and McCann's (2000) argument that the presence of localization economies in larger regions reduces the need for social proximity (e.g., family co-occurrence) by offering more local opportunities to access related knowledge and skills. While social proximity, and family cooccurrence for that matter, may be less relevant in larger specialized regions, our results indicate that social proximity measured as family co-occurrence is indeed associated with higher productivity in specialized regions. This is not surprising because most specialized regions in Sweden are also smaller ones characterized by relatively high shares of family co-occurrence. 
Secondly, different types of familial relationships are beneficial in firms that we defined as family firms (i.e., the owner has family members employed the firm). In this case, relationships involving entrepreneurs and their children and/or spouses positively influence firm productivity. While family cooccurrence in general could be argued to be an important strategic resource, our findings suggest that the family is a constellation of various forms of relationships that affect economic firm outcomes differently (Melin \& Nordqvist, 2007; Wiklund et al., 2013). Our findings also suggest that in family firms where ownership and management are vested in a family, information symmetry between members is enhanced, which in turn has positive effects on productivity (Corbetta \& Salvato, 2004; Cruz, Justo, \& De Castro, 2012; De Massis et al., 2015). Our analyses further indicate that family co-occurrence involving spousal relationships can actually abate the negative effects of having an internal skill mix that is too diverse or too similar (cf. Boschma et al., 2009). This finding is important because it allows us to examine the complementary and substitutional relationships of different types of familial co-occurrence and other factors of production.

In summary, although some have argued that the family has lost its economic significance in modern society, our findings show that not only does the use of informal family network still play an important role in firm recruitment, even in advanced capitalist societies (Ioannides \& Datcher, 2004), it also has a corresponding positive effect on firm productivity. In other words, while family co-occurrence in smaller regions may be a cheaper and quicker means of recruitment, especially for family businesses, it also influences productivity.

\section{Contributions}

Our findings have a number of implications. First, the over-representation of family co-occurrence in workplaces in smaller regions is an indication of the importance of matching firm and regional needs with specific recruitment practices. It is important to reiterate that research on the spatial sorting of skilled workers and firms has shown that the process leaves smaller regions with less productive workers and firms. Therefore, to overcome this problem, managers of SMEs and/or family firms in smaller regions may rely on familial connections to compensate for the lack of diversity, while simultaneously knowing that the process is relatively cost effective. Though this has previously been described as an act of nepotism, it can actually be seen as a process of compensating for a lack of agglomeration economies. We believe this evidence could further inform academic research on the intentions and recruitment practices of SMEs and/or family firms in smaller regions.

Second, our results show that family co-occurrence positively influences firm productivity, especially, familial relationships involving entrepreneurs or firm owners and their children and/or spouses. We expect this finding to inform family business managers the possible trade-offs involving family 
members. It is evident from our findings (in line with other research such as Bird, 2014 and Brannon et al., 2013) that certain familial relationships are more important for productivity, sales, and profitability than others. This should further inform family firm managers the need to harness familial idiosyncratic resources to efficiently leverage familial labour or resources.

Finally, our finding that family co-occurrence, particularly relationships involving entrepreneurs and their spouses, abates the negative effects of having too similar or too different skills should be a concern for scholars in both family business and regional science as well as for family business practitioners. For academic researchers, this finding partially informs previously reported divergence in the effects of skill variety on productivity (Boschma et al., 2009; Östbring \& Lindgren, 2013; Timmermans \& Boschma, 2014). For family business practitioners or owners, it is imperative for them to know that some familial relationships are important contingencies in shaping the economic effects of skill variety.

\section{Future lines of research}

Although we were able to exploit a very rich dataset to further our understanding of the varying productivity effects of different family ties, we encourage further studies to delve more into the potential mechanisms that influence the varying effects of different familial ties (e.g., different trustladen relationships). For example, the results presented here could at least be partially a consequence of the characteristics of the sample and measurements. The data we used were from a population of SMEs, which may not necessarily be representative of family and non-family firms in general even though the former often tend to be rather small. Future studies could therefore examine the relationship between family co-occurrence and firm productivity using larger firms because the family co-occurrence effect may not be the same across all firm sizes.

Further qualitative studies on hiring practices across regions could also be done to better understand the motives behind different types of family recruitment. Another potential future research avenue could be the extent of recruiting couples. Some of our results could be driven by relationships initiated between co-workers, so the presence and potential effects of recruiting couples could be interesting. This is especially relevant in relation to the increasing difficulties of labour sourcing in small regions in combination with over-heated housing markets in many urban regions, which can make it difficult for couples to find affordable housing when forming a family. Finally, the most frequent dyadic relationship we identified is between two men (father and son). Understanding the mechanisms behind the gender differences in family co-occurrence is of critical importance for addressing the issue of gender inequality in family firms. Future studies could therefore address the selection of sons and daughters, respectively, in family firms. 


\section{Acknowledgements}

Parts of this book chapter builds on previously published Open Access (OA) articles in Regional Studies, Regional Science (Adjei et al., 2016) and Entrepreneurship and Regional Development (Adjei et al., 2019). We acknowledge the insightful comments from the editors and the anonymous referees in the process of preparing and revising this chapter.

\section{Note}

1 Full result tables with all variables are available upon request.

\section{References}

Adjei, E. (2018). Relatedness through Kinship: The Importance of Family Cooccurrence for Firm Performance (PhD Thesis), Geography and Economic History, Umeå University, Umeå, Sweden.

Adjei, E., Eriksson, R., \& Lindgren, U. (2016). Social proximity and firm performance: The importance of family member ties in workplaces. Regional Studies, Regional Science, 3(1), 304-320.

Adjei, E., Eriksson, R., Lindgren, U., \& Holm, E. (2019). Familial relationships and firm performance: the impact of entrepreneurial family relationships. Entrepreneurship \& Regional Development, 31(5-6), 357-377.

Alesina, A., \& Giuliano, P. (2014). Family ties. In P. Aghion \& S. N. Durlauf (Eds.), Handbook of Economic Growth (pp. 177-215). Netherlands: Elsevier B.V.

Andersson, M., \& Klaesson, J. (2009). Regional interaction and economic diversity: Exploring the role of geographical overlapping markets for a municipality's diversity in retail and durables. In C. Karlsson, B. Johansson, \& R. Stough (Eds.), Innovation, Agglomeration and Regional Competition (pp. 19-37). Cheltenham: Edward Elgar.

Basco, R. (2015). Family business and regional development: A theoretical model of regional familiness. Journal of Family Business Strategy, 6(4), 259-271.

Bird, M. (2014). The Impact of the Family on Entrepreneurial Outcomes: The Role of Social Embeddedness (Doctoral thesis), Business Administration, Stockholm School of Economics, Sweden.

Bjerke, L., \& Mellander, C. (2017). Moving home again? Never! The locational choices of graduates in Sweden. Annals of Regional Science, 59(3), 707-729.

Boschma, R. (2005). Proximity and innovation: A critical assessment. Regional Studies, 39(1), 61-74.

Boschma, R., Eriksson, R., \& Lindgren, U. (2009). How does labour mobility affect the performance of plants? The importance of relatedness and geographical proximity. Journal of Economic Geography, 9(2), 169-190.

Brannon, D. L., Wiklund, J., \& Haynie, J. M. (2013). The varying effects of family relationships in entrepreneurial teams. Entrepreneurship Theory \& Practice, 37(1), 107-132.

Chirico, F., \& Nordqvist, M. (2010). Dynamic capabilities and transgenerational value creation in family firms: The role of organizational culture. International Small Business Journal, 28(5), 487-504. 
Chrisman, J. J., Chua, J. H., \& Litz, R. A. (2004). Comparing the agency costs of family and non-family firms: Conceptual issues and exploratory evidence. Entrepreneurship Theory \& Practice, 28(4), 335-354.

Combes, P.-P., Duranton, G., Gobillon, L., Puga, D., \& Roux, S. (2012). The productivity advantages of large cities: Distinguishing agglomeration from firm selection. Econometrica, 80(6), 2543-2594.

Corbetta, G., \& Salvato, C. (2004). Self-serving or self-actualizing? Models of man and agency costs in different types of family firms: A commentary on "Comparing the agency costs of family and nonfamily firms: A Conceptual issues and exploratory evidence". Entrepreneurship Theory \& Practice, 28(4), 355-363.

Cruz, C., Justo, R., \& De Castro, J. O. (2012). Does family employment enhance MSEs performance? Integrating socioemotional wealth and family embeddedness perspectives. Journal of Business Venturing, 27(1), 62-76.

De Massis, A., Kotlar, J., Campopiano, G., \& Cassia, L. (2015). The impact of family involvement on SMEs' performance: Theory and evidence. Journal of Small Business Management, 53(4), 924-948.

Duranton, G., Rodríguez-Pose, A., \& Sandall, R. (2009). Family types and the persistence of regional disparities in Europe. Economic Geography, 85(1), $23-47$.

Eriksson, R., \& Lindgren, U. (2009). Localized mobility clusters: Impacts of labour market externalities on firm performance. Journal of Economic Geography, 9(1), $33-53$.

Florida, R., Mellander, C., Stolarick, K., \& Ross, A. (2012). Cities, skills, and wages. Journal of Economic Geography, 12(2), 355-377.

Frenken, K., Van Oort, F., \& Verburg, T. (2007). Related variety, unrelated variety and regional economic growth. Regional Studies, 41(5), 685-697.

Gedajlovic, E., Carney, M., Chrisman, J., \& Kellermanns, F. (2012). The adolescence of family firm research: Taking stock and planning for the future. Journal of Management, 38(4), 1010-1037.

Glaeser, E. L., \& Maré, D. C. (2001). Cities and skills. Journal of Labor Economics, 19(2), 316-342.

Gómez-Mejía, L. R., Núñez-Nickell, M., \& Gutierrez, I. (2001). The role of family ties in agency contracts. Academy of Management Journal, 44(1), 81-95.

Gordon, I. R., \& McCann, P. (2000). Industrial clusters: Complexes, agglomeration, and/or social networks? Urban Studies, 37(3), 513-532.

Gurrieri, A. R. (2008). Knowledge network dissemination in a family-firm sector. Journal of Socio-Economics, 37(6), 2380-2389.

Hasenzagl, R., Hatak, I., \& Frank, H. (2018). Problematizing socioemotional wealth in family firms: a systems-theoretical reframing. Entrepreneurship and Regional Development, 30(1-2), 199-223.

Hollinger, F., \& Haller, M. (1990). Kinship and social networks in modern societies: a cross-cultural comparison among seven nations. European Sociological Review, 6(2), 103-124.

Holm, E., Westin, K., \& Haugen, K. (2017). Place, kinship, and employment. Population, Space and Place, 24(3), 1-12.

Inglehart, R., \& Welzel, C. (2010). Changing mass priorities: The link between modernization and democracy. Perspectives on Politics, 8(2), 551-567.

Ioannides, Y., \& Datcher, L. (2004). Information networks, neighborhood inequality effects. Journal of Economic Literature, 42(4), 1056-1093.

Jacobs, J. (1969). The Economy of Cities. New York: Vintage. 
Jensen, M. C., \& Meckling, W. H. (1976). Theory of the firm: Managerial behavior, agency costs and ownership structure. Journal of Financial Economics, 3(4), 305-360.

Johannisson, B., Caffarena, L. C., Cruz, A. F. D., Epure, M., Pérez, E. H., Kapelko, M., ... Bisignano, A. (2007). Unterstanding the industrial district: Contrasting conceptual images as a road to insight. Entrepreneurship \& Regional Development, 19(6), 527-554.

Korpi, T. (2001). Good friends in bad times? Social networks and job search among the unemployed in Sweden. Acta Sociologica, 44(2), 157-170.

Kramarz, F., \& Nordström-Skans, O. (2014). When strong ties are strong: Networks and youth labour market entry. Review of Economic Studies, 81(3), 1164-1200.

Lengyel, B., \& Eriksson, R. (2016). Co-work networks, labour mobility and productivity in regions. Journal of Economic Geography, 17(3), 635-660.

March, J. G. (1991). Exploration and exploitation in organizational learning. Organization Science, 2(1), 71-87.

Marshall, A. (1920). Principles of Economics: An Introduction Volume (8th ed.). London: Macmillan and Company Limited.

Melin, L., \& Nordqvist, M. (2007). The reflexive dynamics of institutionalization: The case of the family business. Strategic Organization, 5(3), 321-333.

Montgomery, B. J. D. (1991). Social networks and labor-market toward an economic analysis. The American Economic Review, 81(5), 1408-1418.

Östbring, L., \& Lindgren, U. (2013). Labour mobility and plant performance: On the (dis)similarity between labour- and capital-intensive sectors for knowledge diffusion and productivity. Geografiska Annaler Series B - Human Geography, 95(4), 287-305.

Puga, D. (2010). The magnitude and causes of agglomeration economies. Journal of Regional Science, 50(1), 203-219.

Rigby, D., \& Essletzbichler, J. (2002). Agglomeration economies and productivity differences in US cities. Journal of Economic Geography, 2, 407-432.

Riggio, R., \& Saggi, K. (2015). Incorporating "soft skills" into the collaborative problem-solving equation. Industrial and Organizational Psychology, 8(2), 281-284.

Saxenian, A. (1994). Regional Advantage: Culture and Competition in Silicon Valley and Route 128. Cambridge, MA: Harvard University Press.

Schulze, W. S., Lubatkin, M. H., Dino, R. N., \& Buchholtz, A. K. (2001). Agency relationships in family firms: Theory and evidence. Organization Science, 12(2), 99-116.

Timmermans, B., \& Boschma, R. (2014). The effect of intra- and inter-regional labour mobility on plant performance in Denmark: The significance of related labour inflows. Journal of Economic Geography, 14(2), 289-311.

Wenger, E. (2000). Communities of practice and social learning systems. Organization, 7(2), 225-246.

Wiklund, J., Nordqvist, M., Hellerstedt, K., \& Bird, M. (2013). Internal versus external ownership transition in family firms: An embeddedness perspective. Entrepreneurship Theory \& Practice, 37(6), 1319-1340. 